\title{
Application of Latvian illite clays in cosmetic products with sun protection ability
}

\author{
Inga Dušenkova, Iveta Kusiṇa, Juris Mālers, Līga Bērziṇa-Cimdiṇa \\ Riga Technical University, Faculty of Material Science and Applied Chemistry, \\ Institute of General Chemical Engineering. \\ Address: Valdena street 3, Riga, LV-1048, Latvia.
}

\begin{abstract}
Recent research shows that clay minerals can be used in sunscreens as UV filters instead of inorganic and organic compounds, which can cause unexpected photo-catalytic effect and damage the skin surface and can be absorbed into the skin and cause allergic reactions. In this study UV transmittance of suspensions containing clay fraction (mostly illite) and $\mathbf{5 0 \%}$ glycerol/water solution was measured. Samples without chemical treatment, with removed carbonates and iron containing minerals (oxides and hydroxides) were analyzed.

Results showed that the chemical treatment decreased UV protection ability. The highest increase of UV transmittance was observed for samples after removal of iron containing minerals. UV transmittance decreased by $10-14 \%$ when the concentration of clay fraction in the suspension was increased from 20 to 30 mass\%. Samples with the highest concentration of iron oxide showed also the highest UV protection ability.
\end{abstract}

Keywords: carbonates, illite clays, iron compounds, purification, UV transmittance.

\section{INTRODUCTION}

UV radiation has both positive and negative effects on human skin. The positive effect is vitamin D synthesis in the skin, but overexposure to UV radiation can cause sunburn, premature skin aging and skin cancer. There are three types of UV radiation: UV-A (320-400 nm) causes sunburn and skin aging, UV-B (280-320 nm) may cause DNA damage and skin cancer and UV-C $(200-280 \mathrm{~nm})$ is the most dangerous, but it is generally absorbed by the ozone layer $[1,2]$.

Sunscreens can contain both organic and inorganic compounds as UV filters. $\mathrm{TiO}_{2}$ and $\mathrm{ZnO}$ are the most used inorganic compounds, but they can cause an unexpected photo-catalytic effect and damage the skin. The inorganic UV filters are also called physical filters, because their mode of action is based on scattering, reflecting and/or absorbing the sun's radiation [3]. The organic UV filters are usually aromatic compounds with a carbonyl group salicylates, cinnamates, benzophenones and others. They are called chemical filters due to the chemical changes in their molecules that protect the skin from solar radiation. These compounds can be absorbed into the skin and cause allergic reactions $[2,4]$.
One of the potential candidate as natural UV filters in sunscreens are clay minerals, due to their positive impact on human health and chemical inertness. Recent research shows that clay minerals have UV protection ability due to their high specific surface area, therefore providing effective coverage of skin surface. The magnitude of UV protection depends on the clay mineralogical composition $[1,5]$.

The presence of carbonates can cause alkaline media, therefore reducing the efficiency of clay mineral separation from non-clay minerals [6] and can be irritating to the skin [7]. The presence of iron oxides and hydroxides (iron containing minerals) also reduce the efficiency of clay mineral purification [6] and in most cases gives the colour to clays [8]. After the removal of theses iron containing minerals the clay samples become lighter in colour (from light greenish gray to white), therefore expanding their application possibilities, because in cosmetics colour is an essential property.

The sun protection ability is characterized by the sun protection factor (SPF) - a ratio of the least amount of solar energy (UV radiation) required to produce sunburn on sunscreen protected skin to the amount of solar energy required to produce sunburn on unprotected skin [1]. The SPF value depends on the applied amount of the sunscreen - the sun protection 
ability increases by increasing the applied amount [9]. It is recommended to use sunscreen products with an SPF of 15 or higher [1].

The aim of this study was to determine UV protection ability of Latvian illite clays and to evaluate their possible application in sunscreens and other cosmetic products as UV filters.

\section{MATERIALS AND METHODS}

\section{Materials}

Clay samples with different mineralogical composition (Table 1) from four sites in Latvia were used. Laža (La) and Prometejs (Pr) clays are from Quaternary period, Pavāri (Pa) clays are from Devonian period, but Iecava (Ie) clays are from dolomite deposits, were they are as by-product after the purification of dolomite. Sample fraction $<63 \mu \mathrm{m}$ was used, obtained by wet sieving.

Table 1

Mineralogical composition (mass\%) of untreated clays with fraction $<63 \mu \mathrm{m}( \pm$ stdev $)$

\begin{tabular}{lllll}
\hline $\begin{array}{l}\text { Mineral } \\
\text { phase }\end{array}$ & Ie & Pr & La & Pa \\
\hline Illite & $51 \pm 3$ & $51 \pm 2$ & $34 \pm 2$ & $35 \pm 3$ \\
Kaolinite & - & $9 \pm 1$ & $11 \pm 1$ & $4 \pm 2$ \\
Chlorite & - & - & $8 \pm 2$ & - \\
Quartz & $11 \pm 1$ & $14 \pm 1$ & $13 \pm 1$ & $54 \pm 2$ \\
Feldspar & $26 \pm 2$ & $10 \pm 1$ & $16 \pm 1$ & $7 \pm 2$ \\
Dolomite & $4 \pm 1$ & $9 \pm 1$ & $5 \pm 1$ & - \\
Calcite & - & $7 \pm 1$ & $8 \pm 1$ & - \\
Muscovite & $8 \pm 2$ & - & $5 \pm 2$ & - \\
\hline
\end{tabular}

To evaluate the sun protection ability, commercial sunscreens with SPF 15, 30 and 50 were used. All sunscreens contained $\mathrm{TiO}_{2}$ and $\mathrm{ZnO}$.

\section{Purification methods}

$1 \mathrm{M}$ hydrochloric acid solution was used to dissolve carbonates. During the dissolution process the suspensions were stirred and the $\mathrm{pH}$ was kept above 4.5 in order to avoid damaging the structure of clay minerals [6]. When the $\mathrm{pH}$ was $\sim 5$ and stayed constant, the suspensions were centrifuged and all clay samples were washed with distilled water several times, until the electrical conductivity of supernatant liquid was $<100 \mu \mathrm{S} / \mathrm{cm}$. Then clay fraction $<2 \mu \mathrm{m}$ was obtained by centrifugation. These clay samples were referred to as $-\mathrm{HCl}$, for example $\mathrm{La}-\mathrm{HCl}$.

Before the removal of iron oxides and hydroxides, all samples were treated with $\mathrm{HCl}$ in order to dissolve the carbonates. Dry clay samples $(10 \mathrm{~g})$ were mixed with $40 \mathrm{ml}$ of $0.3 \mathrm{M}$ sodium citrate and $5 \mathrm{ml}$ of $1 \mathrm{M}$ sodium bicarbonate solutions. Suspensions were heated to $75-80^{\circ} \mathrm{C}, 1 \mathrm{~g}$ of sodium dithionite was added to each and then mixed for 30 minutes [10]. The colour of suspensions turned blue-green. All suspensions were washed twice with $1 \mathrm{M} \mathrm{NaCl}$ and then with distilled water, until electrical conductivity of the supernatant liquid was $<100 \mu \mathrm{S} / \mathrm{cm}$. Then clay fraction $<2 \mu \mathrm{m}$ was obtained by centrifugation. All treated samples were referred to as -D, for example, La-D.

\section{Preparation of suspensions}

Dry samples were mixed with necessary amount of $50 \%$ (mass $/$ mass) glycerol $/$ water solutions to obtain suspensions with 20 and 30 mass $\%$ of clay fraction. All suspensions were homogenized with disperser T18 Ultra Turrax and matured in locked containers for 2 weeks.

\section{Characterization of the samples}

Determination of chemical composition was conducted with scanning electron microscopy energydispersive X-ray spectroscopy SEM-EDS (Tescan, Mira/LMU). The loss on ignition (LOI) was obtained after heating in $1000^{\circ} \mathrm{C}$ for $4 \mathrm{~h}$.

The sun protection ability of clay fraction/glycerol suspensions was determined by measuring UV transmittance from 290 to $400 \mathrm{~nm}$. UV-VIS spectrophotometer Evolution 300 was used. A small drop of the suspension was applied on $2 \mathrm{~mm}$ thick quartz glass and spread evenly on the whole glass surface $\left(3.14 \mathrm{~cm}^{2}\right)$ with finger, until the sample mass was $0.45 \pm 0.01 \mathrm{mg}$. After 20 minutes UV transmittance was measured in 5 different places. Three parallel measurements were made for each sample and the average result with standard deviation (stdev) was used. The SPF values are calculated from the obtained data using equation (1):

$$
S P F_{\text {ivvitro }}=\frac{\sum_{290}^{400} E_{\lambda} \cdot S_{\lambda}}{\sum_{290}^{400} E_{\lambda} \cdot S_{\lambda} \cdot T_{\lambda}}
$$

where $E_{\lambda}$ is the erythema action spectrum, $S_{\lambda}$ is the solar spectral irradiance, $\mathrm{T}_{\lambda}$ is the spectral transmittance of the sample [9].

\section{RESULTS AND DISCUSSION}

\section{Sample characteristics}

The changes in the colour of samples (Table 2) indicated the removal of iron containing minerals. The brown colour of $\mathrm{La}$ and $\mathrm{Pr}$ samples indicated the presence of goethite and hematite [8], the light gray colour of sample Ie - small amounts of pyrite, but the light beige colour (pinkish white in Munsell colour scale) of sample $\mathrm{Pa}$ indicated low content of iron containing minerals and organic matter [11]. After the removal of iron containing minerals, La-D and Pr-D samples were light gray, Ie-D sample - greenish gray, 
but Pa-D sample - grayish white (white in Munsell colour scale). Because Ie and Pa samples were not brown, the removal of iron containing minerals was proved by the changes in chemical composition, as shown in Table 3.

After the removal of iron containing minerals the amount of iron has decreased by $10 \%$ in sample Ie-D, by $22 \%$ in sample La-D, by $19 \%$ in sample Pr-D and by $3 \%$ in sample $\mathrm{Pa}-\mathrm{D}$ (see Table 3 ). Because $\mathrm{Fe}^{2+}$ and $\mathrm{Fe}^{3+}$ ions can be found in the octahedral sheet of clay mineral structure [12], the rest of iron can be from the structure of clay minerals. The amount of calcium ions also have significantly decreased, due to the removal of carbonates.
Table 2

Colour based on Munsell colour system before and after removal of iron containing minerals

\begin{tabular}{lll}
\hline Samples & Colour & Colour code \\
\hline $\mathrm{Pa}$ & Pinkish white & $7.5 \mathrm{YR} 8 / 2$ \\
$\mathrm{~Pa}-\mathrm{D}$ & White & $7.5 \mathrm{YR} 8 / 1$ \\
$\mathrm{Ie}$ & Light gray & $5 \mathrm{Y} 7 / 1$ \\
$\mathrm{Ie}-\mathrm{D}$ & Light greenish gray & $10 \mathrm{BG} 7 / 1$ \\
$\mathrm{La}$ & Light brown & $7.5 \mathrm{YR} \mathrm{6/4}$ \\
$\mathrm{L}-\mathrm{D}$ & Light gray & $2.5 \mathrm{Y} 7 / 1$ \\
$\mathrm{Pr}$ & Light reddish brown & $5 \mathrm{YR} \mathrm{6/4}$ \\
$\mathrm{Pr}-\mathrm{D}$ & Light gray & $2.5 \mathrm{Y} 7 / 1$ \\
\hline
\end{tabular}

Table 3

Chemical composition (mass $\%$ ) of clay fraction $<2 \mu \mathrm{m}$ before and after removal of iron containing minerals $( \pm \mathrm{stdev})$

\begin{tabular}{|c|c|c|c|c|c|c|c|c|c|}
\hline Sample & $\mathrm{SiO}_{2}$ & $\mathrm{Al}_{2} \mathrm{O}_{3}$ & $\mathrm{Fe}_{2} \mathrm{O}_{3}$ & $\mathrm{CaO}$ & $\mathrm{MgO}$ & $\mathrm{K}_{2} \mathrm{O}$ & $\mathrm{TiO}_{2}$ & $\mathrm{Na}_{2} \mathrm{O}$ & LOI \\
\hline $\mathrm{Ie}$ & $49.6 \pm 1.0$ & $18.5 \pm 0.2$ & $9.0 \pm 0.5$ & $3.9 \pm 0.8$ & $4.3 \pm 0.4$ & $7.1 \pm 0.3$ & $1.0 \pm 0.3$ & $0.3 \pm 0.1$ & $6.8 \pm 0.1$ \\
\hline Ie-D & $52.2 \pm 1.0$ & $19.8 \pm 0.4$ & $8.1 \pm 0.3$ & $0.7 \pm 0.1$ & $4.1 \pm 0.2$ & $8.0 \pm 0.1$ & $1.2 \pm 0.3$ & $0.6 \pm 0.1$ & $5.7 \pm 0.1$ \\
\hline $\operatorname{Pr}$ & $47.3 \pm 1.0$ & $20.4 \pm 1.4$ & $9.7 \pm 0.2$ & $4.2 \pm 0.2$ & $3.7 \pm 0.3$ & $5.2 \pm 0.3$ & $0.6 \pm 0.2$ & $0.6 \pm 0.2$ & $9.1 \pm 0.1$ \\
\hline Pr-D & $53.6 \pm 0.7$ & $21.8 \pm 1.0$ & $7.9 \pm 0.7$ & $0.6 \pm 0.4$ & $3.3 \pm 0.2$ & $5.1 \pm 0.2$ & $0.4 \pm 0.4$ & $1.4 \pm 0.1$ & $6.2 \pm 0.3$ \\
\hline $\mathrm{La}$ & $46.7 \pm 1.1$ & $21.6 \pm 0.8$ & $8.9 \pm 0.4$ & $3.4 \pm 0.3$ & $3.5 \pm 0.2$ & $5.1 \pm 0.2$ & $1.0 \pm 0.1$ & $0.9 \pm 0.1$ & $8.9 \pm 0.1$ \\
\hline La-D & $53.8 \pm 0.9$ & $21.8 \pm 0.2$ & $6.9 \pm 0.4$ & $0.5 \pm 0.1$ & $3.3 \pm 0.3$ & $5.4 \pm 0.2$ & $1.0 \pm 0.4$ & $1.3 \pm 0.2$ & $6.5 \pm 0.1$ \\
\hline $\mathrm{Pa}$ & $56.2 \pm 1.0$ & $24.3 \pm 0.3$ & $7.4 \pm 0.7$ & $0.6 \pm 0.2$ & $2.1 \pm 0.2$ & $5.3 \pm 0.3$ & $1.5 \pm 0.1$ & $0.1 \pm 0.2$ & $2.5 \pm 0.1$ \\
\hline Pa-D & $54.1 \pm 0.9$ & $24.6 \pm 0.7$ & $7.2 \pm 0.3$ & $0.5 \pm 0.1$ & $2.0 \pm 0.2$ & $5.0 \pm 0.2$ & $1.3 \pm 0.1$ & $0.3 \pm 0.1$ & $5.0 \pm 0.1$ \\
\hline
\end{tabular}

\section{Purification influence}

Samples with untreated clay fraction showed the lowest UV transmittance (Fig.1), therefore these samples have higher UV-protection ability than those after removal of carbonates and iron containing minerals. The most significant increase in UV transmittance showed samples after removal of iron containing minerals - approximately $12-18 \%$ higher than for untreated samples. Hoang-Minh et al. research [1] obtained similar results after the treatment with sodium dithionite and explained it with the absence of $\mathrm{Fe}^{3+}$ ions. They stated and proved that UVprotection ability is closely related to the presence of iron containing minerals. For example, hematite $\left(\mathrm{Fe}_{2} \mathrm{O}_{3}\right)$ contains $\mathrm{Fe}^{3+}$ bonded to $\mathrm{O}^{2-}$, where the electron configuration of $\mathrm{Fe}^{3+}$ is characterized by an empty orbital (4s), so that inner electrons can absorb the energy and move from the $3 \mathrm{~d}$ orbital to the $4 \mathrm{~s}$ orbital with a higher energy level. $\mathrm{TiO}_{2}$ particles (specifically $\mathrm{Ti}^{4+}$ ions) have the same UV absorption mechanism. The octahedral sheet in the structure of clay minerals also can contain $\mathrm{Fe}^{3+}$ ions that have an electron configuration with an empty orbital, and thus it should theoretically absorb photons. This assumption was shown experimentally by Chen et al. [13] where the absorption intensity in the UV-C range was directly correlated to structural octahedral contents of $\mathrm{Fe}^{3+}$ in smectite clays. Similar correlation was demonstrated also in clays containing mostly nontronite [1].

\section{Influence of clay fraction concentration}

As the concentration of clay fraction was increased by 10 mass $\%$ (from 20 to 30 mass $\%$ ), UV transmittance decreased by $12-14 \%$ for sample Ie, $11 \%$ for sample La, $10 \%$ for sample Pr and $12 \%$ for sample $\mathrm{Pa}$. Based on the decrease of UV transmittance, the SPF values slightly increased: by $35 \%$ for sample Ie, by $27 \%$ for samples La and Pr, and only by $16 \%$ for sample $\mathrm{Pa}$ (see Table 4 ). Sample Pa showed the highest UV transmittance due to the lowest content of iron containing minerals. 

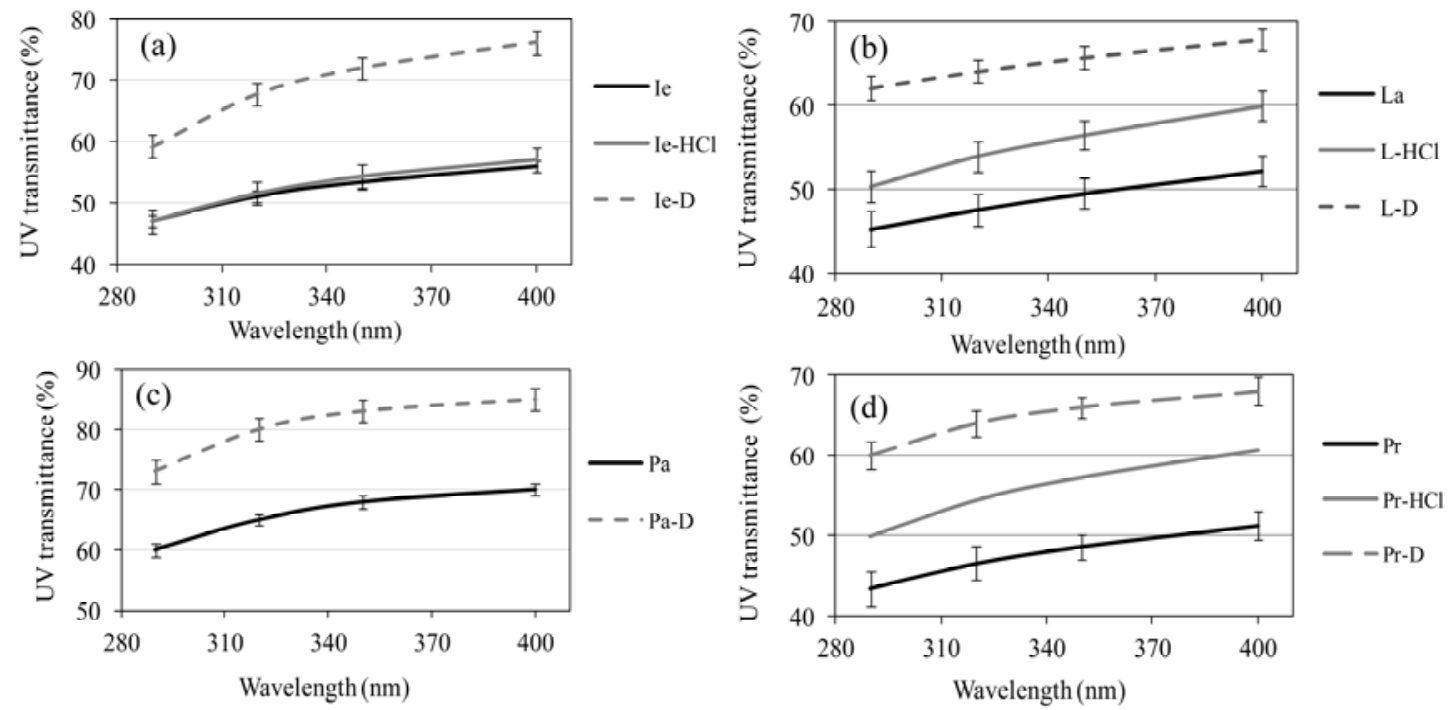

Fig.1. Influence of the used treatment on UV transmittance of Iecava (a), Laža (b), Pavāri (c) and Prometejs (d) clay samples with solid concentration 20 mass $\%$

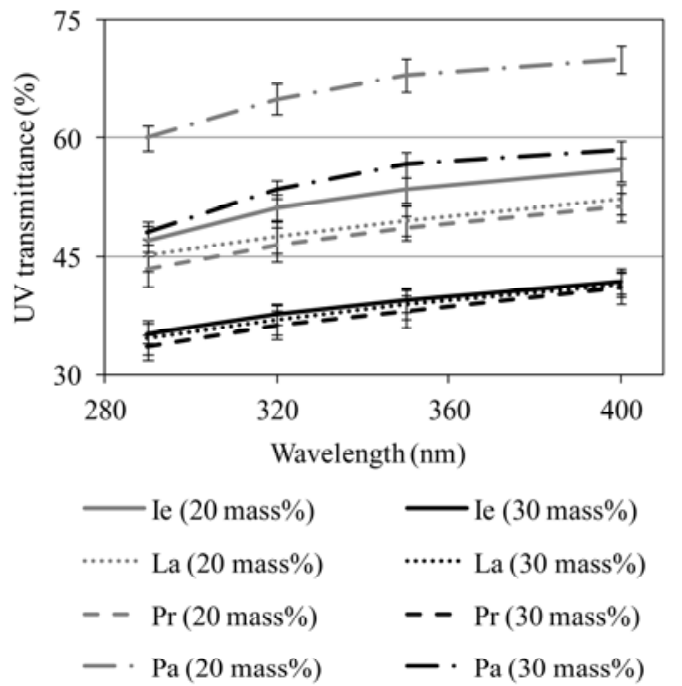

Fig. 2. Influence of clay fraction concentration in the suspension on UV transmittance.

The commercial sunscreens containing $\mathrm{TiO}_{2}$ and $\mathrm{ZnO}$ showed more intensive UV protection abilities in all UV-B and in the beginning of UV-A range (see Fig.3), therefore they also have much higher SPF values $-15,30$ and 50. Pastes and creams containing $\mathrm{TiO}_{2}$ and $\mathrm{ZnO}$ for application as sunscreens tends to be white on the skin, which is unacceptable for cosmetic use, therefore occasionally iron oxide pigments are added to improve the appearance of the product [4]. Because most of the clays in Latvia are brown, they can be used as pigment in sunscreens of tonal creams. At the same time the addition of clay fraction would increase the SPF of the product, thereby decreasing the necessary amount of synthetic UV filters to obtain certain SPF value.

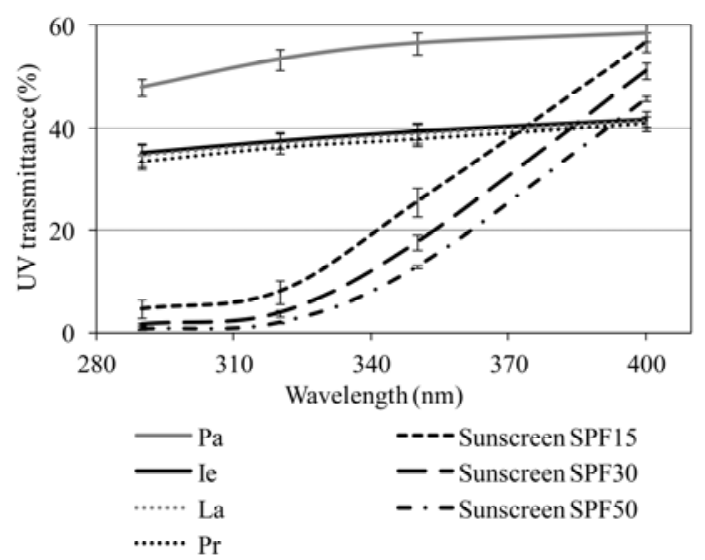

Fig. 3. UV transmittance of commercial sunscreens and suspensions with 30 mass $\%$ of untreated clay fraction.

\section{CONCLUSION}

Illite containing clay fraction samples from Latvian clays showed the ability to partially absorb UV radiation. The influence of the removal of carbonates

Table 4

SPF of untreated clay fraction suspensions in glycerol solution

\begin{tabular}{lll}
\hline Sample & $\begin{array}{l}\text { Concentration of } \\
\text { clay fraction, } \\
\text { mass } \%\end{array}$ & SPF \pm stdev \\
\hline Ie & 20 & $2,0 \pm 0,1$ \\
& 30 & $2,7 \pm 0,1$ \\
$\mathrm{La}$ & 20 & $2,2 \pm 0,1$ \\
& 30 & $2,8 \pm 0,2$ \\
$\mathrm{Pr}$ & 20 & $2,2 \pm 0,1$ \\
& 30 & $2,8 \pm 0,1$ \\
$\mathrm{~Pa}$ & 20 & $1,6 \pm 0,1$ \\
& 30 & $1,9 \pm 0,1$ \\
\hline
\end{tabular}


and iron containing minerals was negative - UV transmittance increased, therefore UV protection properties decreased. From these results it can be concluded, that it is useful to use clay minerals with high content of iron compounds in sunscreens. Despite the relatively low SFP values of clay samples, illite containing clay minerals can be used in sunscreens with low SPF values as one of the UV filters, at the same time giving a light brown colour.

\section{$\mathrm{V}$ ACKNOWLEDGMENTS}

This work has been supported by the National Research Program of Latvia 2014-2017 within the project No.4.4. (Y8099) „Zemes dzīḷu resursu izpēte dabisko izejvielu dažādošanai un jaunu tehnologiju izstrādei (GEO)" (in English - Investigation of underground resources to obtain different natural raw materials and to develop new technologies (GEO)).

\section{REFERENCES}

[1] Hoang-Minh T., Le T.L., Kasbohm J., Giere R. UVprotection characteristics of some clays. Applied Clay Science, 48, 2010, pp. 349.-357.

[2] El-Boury S., Couteau C., Boulande L., et al. Effect of the combination of organic and inorganic filters on the Sun Protection Factor (SPF) determined by in vitro method// Int. J. Pharm. - 2007. - Vol.340. - 1.-5. p.

[3] Smijs T.G., Pavel S. Titanium dioxide and zinc oxide nanoparticles in sunscreens: focus on their safety and effectiveness. Nanotehnology, Science and Applications, 4, 2011, pp. 95.-112.

[4] Serpone N., Dondi D., Albini A. Inorganic and organic UV filters: Their role and efficiency in sunscreens and sun care products. Inorganica Chimica Acta, 360, 2007, pp. 794.-802.

[5] Hoang-Minh T., Le T.L., Kasbohm J., Giere R. Substituting non-natural agents in UV protection cream by a mixture of clay with Ganoderma pfeifferi extract. Applied Clay Science, 53, 2011, pp. 66-72.

[6] Carrado K.A., Decerreau A., Petit S. Synthetic clay minerals and purification of natural clays. Handbook of Clay Science, 2006, pp. 115.-139.

[7] Matike D.M.E., Ekosse G.I.E., Ngole V.M. Physicochemical properties of clayey soils used traditionally for cosmetics in Eastern Cape, South Africa. International Journal of the Physical Sciences, 2011, 33, pp. $7557-7566$

[8] Reeves G.M., Sims I., Cripps J.C. The composition of clay materials. Clay Materials Used in Construction, 2006, pp. 13-27.

[9] Couteau C., Paparis E., El-Bourry-Alami S., Coiffard L.J.M. Influence on SPF of the quantity of sunscreen product applied. International Journal of Pharmaceutics, 2012, 437, pp. 250-252.

[10] Mehra O.P., Jackson M.L. Iron oxide removal from soils and clays by a dithionite-citrate system buffered with sodium bicarbonate. Clays and Clay Minerals, 7 , 1960, pp. 317.-327.

[11] Merriman R.J., Highley D.E., Cameron D.G. Definition and characteristics of very-fine grained sedimentary rocks: clay, mudstone, shale and slate. 2003, pp. 22.

[12] Brigatti M.F., Galan E., Theng B.K.G. Structures and mineralogy of clay minerals. Handbook of Clay Science, 2006, pp. 19-86.

[13] Chen Y., Shaked D., Banin A. The role of structural iron(III) in the UV absorption by smectites. Clay Minerals, 1979, 14, pp. 93-102. 